\title{
"Entomophagy"
}

\section{an evolving terminology in need of review}

Evans, Joshua David; Alemu, Mohammed Hussen; Flore, Roberto; Frøst, Michael Bom; Halloran, Afton Marina Szasz; Jensen, Annette Bruun; Maciel Vergara, Gabriela; MeyerRochow, V.B.; Münke-Svendsen, C.; Olsen, Søren Bøye; Payne, C.; Roos, Nanna; Rozin, P.; Tan, H.S.G.; van Huis, Arnold; Vantomme, Paul; Eilenberg, Jørgen

Published in:

Journal of Insects as Food and Feed

DOI:

10.3920/JIFF2015.0074

Publication date:

2015

Document version

Publisher's PDF, also known as Version of record

Citation for published version (APA):

Evans, J. D., Alemu, M. H., Flore, R., Frøst, M. B., Halloran, A. M. S., Jensen, A. B., Maciel Vergara, G., MeyerRochow, V. B., Münke-Svendsen, C., Olsen, S. B., Payne, C., Roos, N., Rozin, P., Tan, H. S. G., van Huis, A., Vantomme, P., \& Eilenberg, J. (2015). "Entomophagy": an evolving terminology in need of review. Journal of Insects as Food and Feed, 1(4), 293-305. https://doi.org/10.3920/JIFF2015.0074 


\title{
'Entomophagy': an evolving terminology in need of review
}

\author{
J. Evans $^{1^{*}}$, M.H. Alemu ${ }^{2}$, R. Flore ${ }^{1}$, M.B. Frøst ${ }^{1}$, A. Halloran ${ }^{3}$, A.B. Jensen ${ }^{4}$, G. Maciel-Vergara ${ }^{4}$, V.B. Meyer-Rochow ${ }^{5,6}$, \\ C. Münke-Svendsen 7 , S.B. Olsen ${ }^{2}$, C. Payne ${ }^{8}$, N. Roos ${ }^{3}$, P. Rozin ${ }^{9}$, H.S.G. Tan ${ }^{10}$, A. van Huis ${ }^{11}$, P. Vantomme $^{12}$ and \\ J. Eilenberg ${ }^{4}$
}

${ }^{1}$ Nordic Food Lab, University of Copenhagen, Department of Food Science, Rolighedsvej 30, 1958 Frederiksberg C, Copenhagen, Denmark; ${ }^{2}$ University of Copenhagen, Department of Food and Resource Economics, Rolighedsvej 25, 1958 Frederiksberg C, Denmark; ${ }^{3}$ University of Copenhagen, Department of Nutrition, Exercise and Sports, Rolighedsvej 26, 1958 Frederiksberg C, Denmark; ${ }^{4}$ University of Copenhagen, Department of Plant and Environmental Sciences, Thorvaldsensvej 40, 1871 Frederiksberg C, Denmark; ${ }^{5}$ Research Institute of Luminous Organisms, Hachijojima, Tokyo 100-1623, Japan; ${ }^{6}$ Department of Biology, Oulu University, Oulu, Finland; ${ }^{7}$ Stenderupgade 5, 1738 Copenhagen V, Denmark; ${ }^{8}$ University of Oxford, British Heart Foundation Centre on Population Approaches for Non-Communicable Disease Prevention, Nuffield Department of Population Health, Old Road Campus, Roosevelt Drive, Oxford, OX3 7LF, United Kingdom; ${ }^{9}$ University of Pennsylvania, Department of Psychology, Solomon Labs, 3720 Walnut St, Room B15, Philadelphia, PA 19104-6241, USA; ${ }^{10}$ Wageningen University, Food Quality and Design, P.O. Box 17, 6700 AA Wageningen, the Netherlands; ${ }^{11}$ Wageningen University, Laboratory of Entomology, Building 107, P.O. Box 8031, 6700 EH Wageningen, the Netherlands; ${ }^{12}$ Food and Agriculture Organisation of the United Nations, Forest Economic, Policy and Products Division, Forestry Department, Vialle delle Terme do Caracalla, 00100 Rome, Italy; je@nordicfoodlab.org

Received: 31 July 2015 / Accepted: 27 October 2015

(c) 2015 Wageningen Academic Publishers

\section{REVIEW ARTICLE}

\begin{abstract}
There is growing interest in insects as human food in academia, food and agricultural industries, public institutions and the public at large. Yet many of the words and concepts used to describe these organisms and the human practices surrounding them are still rudimentary, compared to the diversity of the organisms themselves and the existing complexity and rapid evolution of the practices they aim to describe. The goals of this paper are to: (1) show how the roots of the term 'entomophagy' and its uses have evolved over time; (2) illustrate some of the term's problems that necessitate its review; and (3) offer recommendations for use of the term in future research and other practice. Our paper offers a brief historical review of insect eating as described by certain Western cultural sources, explores some of the taxonomic ambiguities and challenges surrounding the category 'insects', and ultimately argues for more precise and contextual terminology in this both richly traditional and rapidly developing field.
\end{abstract}

Keywords: biodiversity, edible insects, food systems, othering, taxonomy

\section{Introduction}

'Entomophagy', according to the Oxford Dictionaries Online (http://tinyurl.com/o9zryxq), means 'the practice of eating insects, especially by people.' The construction of 'entomophagy' as a practice uniting otherwise diverse groups has brought attention to the widespread normality of eating insects in many parts of the world - particularly among people who typically do not eat insects but whose interest in these foods is growing, such as some westerners. This surge in global attention has helped to galvanise an international movement around investigating entomophagy's potential for developing more sustainable food systems and valorising traditional diets (Van Huis et al., 2015).

Yet the term also contains some potentially misleading ambiguities, which we address. First the paper will give an overview of some of the historical roots and origin of the term 'entomophagy' in the Western tradition. Then it will outline some of the taxonomic challenges presented by the different registers of the 'insect' category, followed by some 
illustrations of these discrepancies in cultural context. The paper will conclude with reflections on some implications of terminological inadequacy in different fields, and offer recommendations for future use of the term 'entomophagy'. We hope with this paper to initiate further investigation into the cultural, linguistic and conceptual categories that inform our understanding of different classifications of insects and their edibility, and the implications of these categories for diverse fields of human activity.

\section{Methodology and terms}

This paper is a preliminary investigation drawing from the knowledge of the author group and relevant literature. The primary method employed throughout the paper is literature search, covering a range of disciplines: entomology and its subfields, anthropology, biology, ecology, human nutrition, consumer behaviour, psychology, primatology, gastronomy, sociology, sensory science, and others. The literature search was not exhaustive, for linguistic and cultural reasons stated below.

In addition to literature review, part 3 employs analyses of historical texts, dictionaries, and data from Google N-gram viewer and Web of Science searches; part 4 uses analyses from dictionaries and observational case studies from some of the co-authors; part 5 outlines current and potential implications of the terminological issues for different fields of research; and part 6 makes recommendations.

This paper does not represent a comprehensive review of every field it draws from, or of every culture in the world where certain insects may or may not be eaten or where relevant research has been done. Rather, this paper represents a set of illustrative starting points, based primarily on the cultural and linguistic backgrounds and research loci of the co-authors. There is thus a main focus on Western histories and cultures, with many sources written in, transcribed in or translated into English. The authors recognise that many important pieces of research may not be present, particularly some in languages and from regions outside those covered by the group of co-authors.

The paper employs some terms which should be clarified. 'Insects' and 'Insecta' are used to distinguish between different lay and scientific classifications respectively, which will be described further in part 3. 'We' refers to the group of co-authors, unless otherwise stated. 'Western' refers loosely to cultures of European, Mediterranean and/or Levantine derivation, though we readily acknowledge that most contemporary Western societies consist of a number of overlapping and intermingling cultural and ethnic groups.

\section{An evolving terminology}

\section{Historical accounts of insect-eating in Western civilisation}

The practice of eating insects is ancient and widespread among many organisms, and is particularly common among our primate ancestors (Van Huis, 2003), all of which are 'to some degree insectivorous' (O'Malley and McGrew, 2014). Insect consumption is nutritionally significant to all primates (Raubenheimer and Rothman, 2013), and it has been suggested based on the insectivory seen in the chimpanzees (Pan troglodytes) our closest living relatives, that edible insects may have played a key role in our own evolution (McGrew, 2001). 'Insectivory' is a term derived from the Latinate Linnaean class 'Insecta', and is used to describe the consumption of insects by nonhuman animals. It is unclear why the Greek-derived 'entomophagy', with its more recent lexical origin, was designated as the appropriate term for insect consumption by humans (itself a distinction not always acknowledged or employed) - perhaps, ironically, to avoid the othering (let alone 'animalising') of certain human individuals and groups that we are concerned with here (Hooks, 1992; Leer and Kjær, 2015).

One of the oldest written accounts describing insects as food is found in the Old Testament and permits the edible use of 'the locust of any kind, the bald locust of any kind, the cricket of any kind, and the grasshopper of any kind,' (Leviticus 11.20-23, Anonymous, 2001; see Bodenheimer, 1951, p. 40 for an excellent critique of most translations of this passage). Insects are also mentioned in the New Testament, when John the Baptist is 'preaching in the wilderness of Judea', wearing 'a garment of camel hair and a leather belt around his waist' and eating 'locusts and wild honey'. (Matthew 3:1,4, Anonymous, 2001) Later Western accounts include Aristotle's description in the $4^{\text {th }}$ century BCE of cicadas (the nymphs in particular) as a delicacy in Ancient Greece (History of Animals V.30, http:// tinyurl.com/q7hvn9o), a sentiment echoed by Athenaeus of Alexandria in the early $3^{\text {rd }}$ century CE (Deipnosophistoi IV 133b, http://tinyurl.com/nrdkkek), as well as Pliny the Elder's account in the $1^{\text {st }}$ century CE of Romans fattening 'cossus' larvae on flour and wine (Natural History XVII.37, http://tinyurl.com/crmp3bu). See Bodenheimer and Bergier for a satisfying deduction of the identity of the 'cossus' (Bodenheimer, 1951, pp. 42-3; Bergier, 1941, pp. 19-23). Yet for our purposes of excavating a genealogy of the term 'entomophagy', the first recorded etic encounters may be more pertinent. This may be from Herodotus of Halicarnassus in the $5^{\text {th }}$ century CE when he describes the Nasamonians, who along with gathering palm dates 'hunt the wingless locusts, and they dry them in the sun and then pound them up, and after that they sprinkle them upon milk and drink them' (The Histories IV.172, http://tinyurl.com/ 
p3mmcwl). Later on in the early $3^{\text {rd }}$ century CE, Aelian of Rome describes a dessert of larvae from the tawny palm served by a King of India to a group of Greek visitors; the Greeks did not like it (Bodenheimer, 1951, p. 43).

Even from these few historical sources, we see that: evidence for humans eating and delighting in certain insect species extends back at least a couple of millennia; and each practice described had its particular context, species, and conditions of appropriateness.

\section{Origin of the term 'entomophagy'}

The term 'entomophagy' itself, at least in English and some other European languages, is rather new. Even Aldrovandi's 'De animalibus insectis' from the beginning of the $17^{\text {th }}$ century, which includes information on insects' use for food and which signals the start of the 'new age of entomology' (Bodenheimer, 1951, p. 44) does not contain the term. The Oxford English Dictionary (2015a) has an entry for it, though with no record of its coinage. Google $\mathrm{N}$-gram currently dates the first published mention of 'entomophagy' to 1871, in a volume entitled 'Sixth annual report on the noxious, beneficial and other insects of the state of Missouri' by Charles V. Riley, state entomologist, which itself refers to a paper by W.R. Gerard entitled 'Entomophagy' which 'in the same year... ha[d] brought together all the facts [known of the practice and was] read before the Poughkeepsie Society of Natural History' (http:// tinyurl.com/njpusnl; Riley, 1871). Alas the authors were unable to find Gerard's eponymous paper itself. Published records of the term continue to appear throughout the 1870s and 1880s - including the notable publication of Vincent Holt's Why not eat insects (Holt, 1885), arguably the first document to bring the notion of entomophagy to the wider English public - dropping off for a few decades then returning around 1934 to steadily increase until today (http://tinyurl.com/njpusnl). See Table 1 for first published mentions of 'entomophagy' and its analogues in a few other languages. The beginning of this $20^{\text {th }}$ century resurgence coincides with a boom in the fields of anthropology and ethnology, in particular ethno-entomology and cultural entomology (Bergier, 1941; Hogue, 1987; Schimitschek, 1961, 1968), as evidenced for example by Bodenheimer's seminal publication in 1951 - who himself implies (p. 7) honey consumption as also a type of entomophagy. This position is not the most common today, although it is somewhat analogous to categorising the consumption of animals and their products together, as veganism does. It should also be said that some of the publications from this period do not seem to distinguish between 'entomophagy' and 'insectivory' as previously described. This distinction may also not necessarily exist beyond English, even within the romance languages; French, for example, seems to have used the words interchangeably (Anonymous, 2014), even
Table 1. First published mentions of 'entomophagy' and a few of its analogues. ${ }^{1}$

\begin{tabular}{|c|c|c|}
\hline Language & Word & First published mention \\
\hline English & entomophagy & Riley, 1871 \\
\hline French & entomophagie & Virey, $1810^{2}$ \\
\hline Spanish & entomofagia & Anonymous, 1919 \\
\hline \multicolumn{3}{|c|}{$\begin{array}{l}1 \text { It should be noted that Google } \mathrm{N} \text {-gram is not a complete record of } \\
\text { every document ever published, but at this point it may be the most } \\
\text { comprehensive digital database available. These data were obtained } \\
\text { from a case-insensitive search. }\end{array}$} \\
\hline
\end{tabular}

in light of the recent addition in 2015 of 'entomophagie' to Le Petit Robert (Aissaoui and Valmalle, 2015).

Even current definitions of 'entomophagy' do not necessarily make such a clear distinction. While Oxford Dictionaries Online (http://tinyurl.com/o9zryxq), as described in the introduction, defines the term as 'the practice of eating insects, especially by people', the more discipline-specific 'A dictionary of entomology' (Gordh and Headrick, 2011) lists 'entomophagy' as 'consumption of insects by other organisms'; there is an ambiguity here, as 'other organisms' could be taken to mean the set of all organisms including or excluding insects. The same book defines 'insectivore' as 'an organism which eats insects', which could include consumption by all organisms including insects; and defines 'insectivorous' as 'insect-eating; pertaining to organisms subsisting on insects' (italics added) - the only place which hints at a firmer distinction between 'entomophagy' and 'insectivory', where the former could describe a behaviour of eating insects in a specific situation, and the latter more a behavioural pattern or habit of eating primarily or only insects as a rule (Meyer-Rochow, 2010). This distinction might also be generalised to other eaten objects having both '-phagy'- and '-vory'-suffixed words. We can compare 'insectivory' in this sense with other terms of similar construction ('herbivory,' 'carnivory', 'omnivory') describing general dietary patterns more than specific instances of food choice.

We also found an interesting pattern when looking into Web of Science, using 'entomophagy' as a search term for scientific papers in English over time (Table 2). From 1900-1980 only two articles were found (1930 and 1938), and in both cases the studies were about insects practicing 'entomophagy' (i.e. 'insectivory'). From 1981-1990 there is one article published, an evaluation of a book about human consumption of insects among aboriginals in Australia. From 1991-2000 and 2001-2010 there are 15 and 16 articles using 'entomophagy', respectively, with some using the 
'human consumption of insects' definition and others using that of 'insect consumption by other animals' ('insectivory'). The number of papers has since multiplied - between 2011 and mid-2015 there have been 49 entries, most of which deal with human consumption of insects and many with a focus on traditional foraging of insects (ethno-entomology).

Looy et al. (2014) describe a likely mechanism for how the term 'entomophagy' developed into the more anthropological term in use today:

Anthropologists... expressed puzzlement at the apparent health and vigor of peoples whose food sources seemed to lack essential amino acids, vitamins, and minerals. It took many years before some realized these nutrients were supplied through entomophagy (Harris, 1985; Schiefenhövel and Blum, 2007). Even today relatively few studies of cultural foodways include recognition of entomophagy, and this lack is attributed more to the bias of the researchers than the infrequency of the practice (Harris, 1985; Schiefenhövel and Blum, 2007). We also find it telling that Western researchers give the practice of eating insects a distinctive term entomophagy - that to our students in class sounds more like a disease than a descriptor, and that an important anthropological article on entomophagy is published in a collection entitled Consuming the Inedible (Schiefenhövel and Blum, 2007).

In other words, it is likely that 'entomophagy' was used by largely non-insect-eating researchers to denote an eating habit that was not appropriate in their own cultures. The title of Bergier's 1941 work, 'Peuples entomophages et insects comestibles' (Entomophagous people and edible insects), for example, clearly illustrates this perspective. His work cites examples of human insect-eating from all over the world, while his chapter on Europe (his home continent) deals mainly with the ancient history of the Greeks and Romans, distant enough in time to qualify as different-enough cultures. The word thus developed from being a general to a primarily anthropological term, associated with observations of humans eating insects in tropical 'other' countries and with certain cultural groups. This fact is now of course evolving, and with it so must our understanding and use of the term.

\section{A terminology in need of review}

\section{'Insects' versus 'Insecta': a taxonomic issue}

Before we can adequately address the terminological issues of 'entomophagy' itself, we first examine the terminological issues of the organisms with which the term is concerned: 'insects'. The main issue is one of taxonomy. The term is used in different contexts, in reference both to different taxa within scientific classification, as well as to different categories in lay or folk classification systems. The simplest and most technical way to define insects is by direct correspondence to the Linnean class Insecta. The taxon, part of the phylum Arthropoda, is comprised of over one million species described and around five million total species estimated (Chapman, 2006). It is thus one of the most diverse class of animals on the planet and represents more than half of all known living multicellular eukaryotes (Chapman, 2006; Novotny et al., 2002). Insecta includes many orders, of which the most common and speciose are: Coleoptera (beetles), Lepidoptera (butterflies and moths), Diptera (true flies), Hymenoptera (bees, ants, wasps), Orthoptera (grasshoppers and crickets) and Hemiptera (true bugs, cicadas, aphids). There are about 23 other orders (Misof et al., 2014).

Yet this technical definition of 'insect' used by most specialists and professionals differs from the informal, vernacular meaning in English of 'any small invertebrate animal' (Oxford Dictionaries Online, http://tinyurl.com/ q48gjze), which can be employed both loosely and with significant variation between speakers. This broader and more fluid category of 'insect', sometimes but not always analogous to 'bug' (https://en.wikipedia.org/wiki/Bug), has different layered subsets that build on the core group of

Table 2. Publications in Web of Science containing 'entomophagy', 1900-present. ${ }^{1}$

$\begin{array}{lcl}\text { Period } & \text { \# of articles } & \text { 'entomophagy' in articles from Web of Science } \\ 1900-1980 & 2 & \text { consumption by other insects ('insectivory') } \\ 1981-1990 & 1 & \text { consumption by humans } \\ 1991-2000 & 15 & \text { mix of consumption by humans and by other organisms } \\ 2001-2010 & 16 & \text { mix of consumption by humans and by other organisms } \\ 2011-2015 & 49 & \text { predominantly consumption by humans }\end{array}$

${ }^{1}$ It should be noted that Web of Science, like any database, is biased - in this case that there is less comprehensive coverage of articles published prior to 1980 . Thus the figure of only 2 articles may be an underestimation of the total number of articles or books mentioning 'entomophagy', even in English, for this time period. 
Insecta, as laid out in Figure 1. The subphylum Hexapoda contains the Ectognatha, those six-legged arthropods with external mouths (comprised of Insecta), as well as the Entognatha, six-legged arthropods with internal mouths, including the Diplura, Protura, and Collembola. Beyond the Hexapoda come other Arthropoda, including those of the Arachnida (spiders, scorpions, mites), Myriapoda (centipedes, millipedes), and Crustacea (woodlice, crabs) a vernacular relation particularly divergent from scientific taxonomy in light of the recent suggestion that Insecta are actually much more closely related to Crustacea than other subphyla (Pennisi, 2015). At this point a taxonomist might be impelled to snap the vernacular English category back to technical rigour with the descriptor 'terrestrial arthropods' i.e. all members of the Arthropoda which live on land. But this definition then excludes all the various aquatic 'insects' that are eaten (and there are a lot), as well as certain other organisms sometimes included in the vernacular category such as earthworms (Annelida) and snails and slugs (Gastropoda of the phylum Mollusca). And in some situations, for example in parts of South America, the 'insect' category might extend even further to include vertebrates such as snakes, toads, lizards, and others (CostaNeto, 2000).

Furthermore, even if many entomologists subscribe to a strict definition of 'Insecta' in principle, few employ such a narrow category in their own practice. A brief and nonsystematic survey of scientific entomological journals and conferences quickly shows it to be common to also include Arachnida and Myriapoda in the professional 'insect' category.

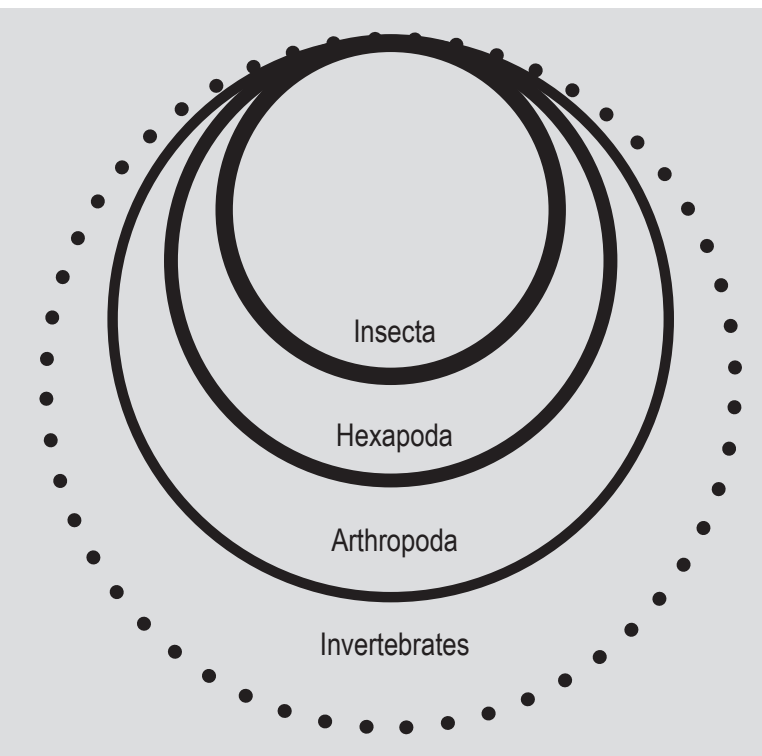

Figure 1. Relative subsets of the vernacular category 'insect', also sometimes analogous with 'bug'. Other possible configurations exist.

\section{Diverse insect-eating practices}

It should go without saying that not all 'entomophagists' eat all insects, just as not all meat-eaters eat all types of meat from all animals. In cultures where insects are food, there are clear and localised norms regarding which species are considered to be edible, and how they are most appropriately prepared and consumed (Menzel and D'Aluisio, 1998). We feel it is prudent to demonstrate this fact with a few examples.

In sub-Saharan Africa, different, often nearby ethnic groups have different preferences. Van Huis (2003), citing Barreteau (1999) and Lévy-Luxereau (1980), describes how 'the MofuGudur in Cameroon eat a number of grasshopper species (Acorypha picta, A. glaucopsis, Acrida bicolor, Oedaleus senegalensis, Pyrgomorpha cognata, Truxalis johnstoni), which are not eaten by the Haussa in Niger, while the Haussa but not the Mofu-Gudur eat Humbe tenuicornis.' There are also many examples of prohibitions against eating insects within ethnic groups, such as 'Pygmies [who] eat the larvae and the nymphs of the Goliath beetle, but not the adult which is considered sacred and used in fetishes (Bergier, 1941: p. 60). See Van Huis (2003) for further examples.

Tan et al. (2015) examined the consumer perceptions and acceptance of insects in two countries (the Netherlands and Thailand) where the degree and nature of experiences regarding insects as food differ greatly. Dutch participants were mainly concerned with sustainability, while Thai participants were mainly concerned with taste and culinary familiarity. The Thai had a strong preference for ant larvae, grasshoppers, and giant water bugs (familiar species in Thai cuisines), and were strongly repulsed by the mealworms (with similar results for mopane worms and wichetty grubs), which bear no resemblance to a food insect in Thai cooking and are associated most closely with putrefaction. The Dutch, on the other hand, were familiar with mealworms more as a potential 'sustainable' food source due to their recent availability on the market and offerings at public events, and were thus more willing to try them.

In other non-Western cultures where insect species are traditionally included in the diet, this practice may not be reflected in the vocabulary (Case 1).

It is worth mentioning that available nutritive substances in taxonomic categories other than insects are also rejected (Simoons, 1978), and that this selectivity is exhibited not only by humans but also by other animal species of the animal kingdom. Certain human communities in Africa, for example, have in the past rejected fish as food (Simoons, 1974). Many wild plant species considered edible in some regions of Europe are regarded as pest species in others (Turner et al., 2011). Wild chimpanzee communities are also selective in their food choices: protein-rich oil palm nuts, for 
Case 1. Gabriela Maciel-Vergara, from the insecteating region of Hidalgo, Mexico: 'I come from a country where eating insects is a common practice, and we don't use the term 'entomophagy' at all in our vocabulary. Nor do we have a term for those who do not eat insects - my mom, for example is horrified by the idea of eating them, but she is keen to buy and cook them for our family. We know it is a matter of personal preference, strongly influenced by exposure during childhood and the local custom of one's region - though we don't distinguish between those who choose to eat insects and those who don't.'

example, are ignored by chimpanzees in Western Uganda (McGrew et al., 2010) yet are a valued food item among a well-studied group in Guinea (Humle and Matsuzawa, 2004). In chimpanzees, as in humans, patterns of food cultures - and indeed insectivory (Webster et al., 2014) cannot be explained solely by ecological or genetic factors (Lycett et al., 2007). In general in human cultures, food taboos are complicated and those involving insect species are no exception (Meyer-Rochow, 2009).

\section{Classification discrepancies in cultural context}

Discrepancies in practice between 'insects' and 'Insecta' abound, and not only within English. The range of vernacular versions of 'insects' that extend beyond 'Insecta' is broad and can vary significantly between different human cultures.

In Western Kenya, the Luo and Luhya tribes eat lake flies, termites, and black ants (Ayieko and Oriaro, 2008; Ayieko et al., 2012; Christensen et al., 2006; Kinyuru et al., 2009; Van Huis et al., 2013). Within these two tribal cultures, the classification of insects are different (Case 2).

Case 2. Josh Evans, with two other researchers: 'On field work in Western Kenia in 2013, our team observed lay conceptions of the 'insects' category varying according to tribal eating practice. Most Luo and Luhya we interviewed did not assign their Dipteran, Isopteran, or Hymenopteran delicacies to the category 'insect' at all, but used this descriptor solely for those terrestrial arthropods which they did not eat, particularly pests, such as termite species which are not eaten.'

A similar vernacular classification strategy has been observed by other researchers (Yates-Doerr, 2012), where differentiating between 'insects' and 'edible insects' proves all the difference (M.H. Alemu, unpublished data).

Josh Evans and his fellow researchers observed a similar pattern when conducting field work in Sardinia (Case 3).

Case 3. Josh Evans, with two other researchers: 'In Sardinia, the larvae of the cheese fly Piophila case $i$ are involved in the transformation of local cheeses such as pecorino and casizolu into casu marzu, a local delicacy in which the larvae are eaten along with the cheese. Here we observed that many Sardinians who care deeply for this cheese did not even consider it to contain 'insects' let alone that they themselves eat 'insects', and when offered to try another member of Insecta (Locusta migratoria, not whole but in the form of a fermented soy-sauce-like product developed at Nordic Food Lab) expressed observable distaste at the thought.'

Roberto Flore, at the time the Nordic Food Lab team's field guide in Sardinia and now a part of the team, is himself Sardinian and speaks emically to this fact, which for some outsiders may appear as a paradox but which contains its own implicit cultural logic (Case 4).

Case 4. Roberto Flore, from Seneghe, Sardinia: 'It is funny but I realized I was part of 'Entomophagy' culture only when I tasted a grasshopper for the first time some years ago. Most of the people I know in Sardinia don't see Casu Marzu as directly related to similar practices of eating insects in other parts of the world. For us it is just a product, a cheese, a delicacy, but we don't think we are eating insects. At the same time my friends in Sardinia are not interested to eat other types of insect. In this case, one problem with the current terminology is that it creates a big group of people who do not share the same vision of what 'eating insects' actually means.'

Analogous versions of this cheese also occur/are produced and eaten in some other Italian provinces ('cacie' punt' in Molise, 'formaggio saltarello' in Friuli Venezia Giulia, 'pecorino marcetto' in Abruzzo, among others), in Corsica ('u casgiu merzu') and in Croatia ('trulo sir'; Miokovic and Kozacinski, 2003), where it would be fruitful to research whether similar patterns of vernacular classifications may exist. 
Japanese insect-eating cultures also exhibit interesting distinctions. The Japanese system of classification uses two terms: 'konchū' (昆虫) and 'mushi' (虫). 'konchū' refers to the order Insecta but 'mushi' is a more colloquial term and particularly among older generations is often extended to include snails, slugs, millipedes, scorpions, and even frogs and snakes. The kanji characters that refer to these animals also contain the 'mushi' (虫) symbol (e.g. snake=hebi=蛇). The term 'mushi' is also used to refer to one's emotional state and idiomatic expressions involving 'mushi' tend to locate them inside a person's belly ('hara'), such as the phrase: 'hara no mushi ga osomaranai', or '[my] belly worms cannot be pacified', which means 'I cannot control my emotions'. In this use, the notion of 'mushi' is less that of 'other' and more that of being intimately of the self. Perhaps this reflects the way in which insects themselves are indeed appreciated in Japanese culture, often appearing in art and referred to poetically in literature. The song of singing insects, for example, is particularly cherished (Ryan, 1996).

However, as Laurent (1995) notes, 'mushi' is often used as a relative term in Japanese, and can also have negative connotations of being unclean, troublesome, distasteful, and untouchable. Within insects, a wild green silkworm may be considered 'more' of a 'mushi' than the more culturally valued white domesticated silkworm (Laurent, 1995). Similarly with regard to food insects, edible species may be considered an anomaly within the category of 'mushi', and not really 'mushi' at all, which is also not an attitude exclusive to the elderly. For example, one co-author (C. Payne) was told during the course of her fieldwork, 'I eat wasps! But I don't eat mushi,' by a young girl in her teens (C. Payne, personal comment). As with the silkworm and fireflies mentioned by Laurent (1995), the edible wasps were considered to be mushi in general, but not when eaten.

\section{Intercultural relations around 'strange' eating habits}

It is no coincidence that the term and concept of 'entomophagy' are conspicuously absent from the lexica of most cultures where insects are eaten (exceptions, of course, include cultures with pre-colonial insect-eating and the subsequent adoption of 'entomophagy'-containing colonial languages - Spanish in Latin America, for example). As a parallel, there is no analogous term in Europe among European languages for 'the eating of crustaceans' (crustaceáphagy?), the mostly aquatic arthropods whose terrestrial cousins we call 'insects' (Pennisi, 2015). In historical-cultural perspective this asymmetry makes sense, as crustaceaphagous European cultures had no need of an emic description for the practice, which has been normalised for quite some time, while these same cultures have only relatively recently started paying more attention to cultures where insect-eating is analogously commonplace.
Closer analysis of other '-phagy'-suffixed words reveals further nuances. Common lists of such words, also containing 'entomophagy' (http://tinyurl.com/osoezdg; http://tinyurl.com/pjetsqs), are often titled along such lines as 'Lists of feeding behaviours' (italics added), in which terms like 'entomophagy' are in such predominant company as 'hyalophagy' (the eating of glass), a habit generally regarded as inappropriate or even pathological in many not only Western cultures, and 'adelphophagy' (the eating of one embryo by another in utero), a term used almost exclusively in relation to certain amphibians, sharks, and fish. The few other terms on these lists whose corresponding practices are considered appropriate in some human cultural contexts - such as 'acridophagy' (the eating of grasshoppers and locusts), 'encephalophagy' (the eating of brain), 'geophagy' (the eating of earth, soil or clay), 'haemotophagy' (the eating of blood), 'hippophagy' (the eating of horse), 'myrmecophagy' (the eating of ants), 'ophiophagy' (the eating of snakes), or 'placentophagy' (the eating of placentae) - nonetheless more often denote eating habits, or shall we say 'feeding behaviours', of animals. Even if English-speakers do not intend it, and even if there now exists a technical term to differentiate between human and animal behaviour such as 'insectivory' (regardless

Table 3. A selection of English words ending in -phagy, their meanings and associations. ${ }^{1}$

\begin{tabular}{|c|c|}
\hline -phagy term & Meaning \\
\hline acridophagy & eating of grasshoppers/locusts \\
\hline anthropophagy & eating of humans \\
\hline adelphophagy & eating of one embryo by another in utero \\
\hline arachnophagy & eating of spiders \\
\hline coprophagy & eating of feces \\
\hline encephalophagy & eating of brains \\
\hline entomophagy & eating of insects \\
\hline geophagy & eating of earth, chalk, clay \\
\hline haemotophagy & eating of blood \\
\hline hippophagy & eating of horse \\
\hline hyalophagy & eating of glass \\
\hline myrmecophagy & eating of ants \\
\hline necrophagy & eating of dead/decaying flesh \\
\hline ophiophagy & eating of snakes \\
\hline oophagy & eating of eggs/embryos \\
\hline placentophagy & eating of placentae \\
\hline \multicolumn{2}{|c|}{$\begin{array}{l}{ }^{1} \text { All terms could refer to an animal behaviour, a human behaviour accepted } \\
\text { in one culture but not that of the observer/speaker, and/or a human } \\
\text { pathological behaviour. Depending on the context their meanings can } \\
\text { shift, and all in some way imply that the practice they describe is culturally } \\
\text { inappropriate, for one or more of these reasons (http://tinyurl.com/osoezdg; } \\
\text { http://tinyurl.com/pjetsqs). }\end{array}$} \\
\hline
\end{tabular}


of how rigorously they are deployed), employing a term such as 'entomophagy' to describe human eating habits also automatically deploys this historical and cultural baggage, such as the association of a classical etymological formation with animal or pathological behaviours and a correspondingly diagnostic tone. These examples and more are listed in Table 3.

Such issues are not only present in English. In German, for example, the term 'Entomophagie' only begins to appear in relatively recent publications, yet previous work from 1955 and 1968 , based on travel diaries from the $18^{\text {th }}$ century, use the pejorative terms 'Insektfresser' and 'Insektesser' to describe people eating or 'feeding' ('fressen') on insects (Schimitschek, 1961). Similarly, in Dutch, the closest analogue to 'entomophagy' is 'Eulipotyphla', used for both humans and other animals, a word which describes the now-defunct taxonomic order Insectivora (lit. 'insecteaters') which used to include hedgehogs, moles, shrews and other mammals which did not fit easily into earlier existing taxa. The parallels in both of these terms to animal feeding behaviour are clear indeed.

Certainly every culture finds ways to describe cultures different from their own; yet our concern here is that committing to a universal concept which implicitly frames eating insects as inappropriate, paired with the dominance and pervasiveness of Western cultural values, is contributing to at least two detrimental processes: (1) a growing rejection in many insect-eating cultures of important and locally advantageous foodways to conform to Western cultural norms (Meyer-Rochow, 1975a); and (2) to the unnecessary, if less obvious, impediments the same term, because of the inappropriateness it implies, poses to members of as yet non-insect-eating cultures.

\section{The implications and role of terminology in future work}

\section{Taxonomy and classification}

Sensitivity to the different registers of classifications for 'insects' is crucial for future research. Scientific taxonomy is not always the most accurate or precise classification of organisms (Berlin, 1992; Posey, 1984) and in many vernacular classifications the category 'insect' is not only or even primarily a morphological/phylogenetic category, but also an affective, ideological, and ethnological one (CostaNeto, 2000). For example, Meyer-Rochow (1975b) describes how in some contexts, insects are classified according to their behavioural similarities (e.g. one name for flea and jumping spider, a collective name for all insects drawn to light at night), their importance as food (e.g. larval instars, adult males and adult females of the same scientific species having different terms) and their importance as harmful creatures (as distinguished from less harmful insects).
Different configurations of the vernacular 'insect' category are also regularly used by researchers for practical purposes, prioritising descriptive power over taxonomic precision (Holt, 1885; Kellert, 1993; Looy et al., 2014; Misof et al., 2014). Failure to recognise different classification schemes obstructs the knowledge exchange crucial for developing a richer appreciation of insects' edible potential (Sileshi et al., 2009). Moreover, it can further marginalise cultures where insects are not only eaten but classified differently (Johnston and Baumann, 2007; Looy et al., 2014).

\section{Environmental and nutritional research on insects as food and feed}

Many insects have been demonstrated to be rich in certain proteins, fats, fibre, and/or micronutrients (Bukkens, 1997; DeFoliart, 1992; Ramos-Elorduy et al., 1997), with ecological benefits and relatively low environmental impacts (Van Huis et al., 2013). Yet, insects are also a very diverse category of organisms: the current estimate of eaten insect species is 2037 (Jongema, 2015), and this figure will likely be a small number of the total number of species that are nutritious and safe to consume. This species diversity covers a broad range of geographical distributions, ecological roles, environmental impacts, and nutritional profiles, by species, life stage, and processing method (Bukkens, 1997; Hanboonsong et al., 2013; Kinyuru et al., 2012; Lundy and Parrella, 2015). Furthermore, species also vary in their advantages and limitations during mass production (Hanboonsong et al., 2013; Lundy and Parrella, 2015), and in their status as food within and across cultures (Obopile and Seeletso, 2013; Tan et al., 2015). The literature is giving more and more attention to this diversity; popular dissemination should similarly acknowledge this huge range of properties, and express more precisely which ecological and nutritional characteristics are associated with specific species and under which conditions.

\section{Gastronomy}

If those who do not currently eat any insects are to embrace certain species as food, they will have to come to consider insects as 'food' and not solely as 'nutrient'. Differences in physicochemical composition contribute to different tastes and textures, which is why different species are prepared in different manners by those who already eat them (Evans, 2014; Halloran et al., 2015b). Familiarity with a product breeds distinction: eaters develop relationships with the different meats, fish, fruits, vegetables, grains and other foodstuffs familiar to their culture with corresponding specificity (Rozin and Rozin, 1981). In the case of insects for current non-eaters, however, the use of a single homogenising term tends to constrain this process of differentiation necessary to the development of cuisine as a system of culturally appropriate eating practices (Rozin and Rozin, 1981). To use the collective benefits and widespread 
practice of consuming insects as rational arguments for their introduction as food to is unlikely to be effective, similarly to how the nutritional value and enjoyment of certain meats does not mean that all animals would or should be accepted as food by everyone everywhere. Indeed:

Insects [should] not just be seen as one item to be placed under an existing familiar food category, such as meat. Trying to extend an existing food category to include insects misses the fact that the real challenge is category distinction, and not category extension: people's initial single category of insects has to allow for a distinction to be made between inedible and edible insects, and the latter set has then to be seen as a source of rich variety, open for distinct food experiences, and pleasures. (Deroy et al., 2015)

The general concept of 'eating insects' can be a first step, but certainly not the last. In the same way that we understand 'fish' as a general category but when we cook and eat we do so with 'cod' and 'sardines' and 'monkfish' and 'salmon' and sometimes even 'Norwegian salmon' or 'Baltic salmon', 'coho' or 'sockeye' or 'spring' salmon, early or late in the season, at different distances from their home river, etc. - so must we also develop progressively more specific knowledge and tastes when it comes to insects and their roles in different cuisines. Actively engaging in this coevolution of available foods and the language we use to describe them is a crucial step in developing the gastronomic knowledge between different species, developmental stages, anatomical parts, times of year, and other factors necessary to make these differences palatable and celebrated (Evans et al., 2015, Halloran et al., 2015a,b).

\section{Consumer perceptions and acceptance}

The naming and descriptive labelling of dishes both novel (Mielby and Frøst, 2010) and familiar (Wansink et al., 2005) have been shown to strongly influence their appeal, and the association of novel foods to familiar foods within current diets could also improve the willingness to try them (Tuorila et al., 1998). As Looy et al. (2014) put it, 'the challenge is to persuade an insectphobic [sic] culture to recognise these creatures as a legitimate food resource' Most people in India and the USA, for example, find insects as food disgusting (Ruby et al., 2015) - even though these countries, particularly the former, have large and diverse populations, with some regions where many insects are eaten, such as in North-east India (Chakravorty et al., 2013). Communicating insect-based food products to non-insecteating consumers using the word 'entomophagy' may turn out to be detrimental, unless the consumers' perception of the word can be altered so that it is to a greater extent associated with edibility, appropriateness, low food risk and a positive social history (Martins and Pliner, 2005; Rozin, 1990; Rozin and Fallon, 1987).
People tend not to conceptualize the foods they eat in terms of taxonomic categories (e.g. mammals, birds, fungi), which could bring about different sets of associations when these categories are mentioned. Consumer judgments are generally formed based on what is known about a category (Bar-Anan et al., 2006), which in the case of insects, unfortunately often tends to relate to the frequent encounters with insects as pests, disease-carriers, indicators of poor hygiene, and morphological aliens vis à vis humans (Harris, 1985; Kellert, 1993). Yet consumers who find the idea of eating 'insects' offensive were also found to express more positivity towards certain insect species and preparations when presented with contextualized images and/or products (Caparros Megido et al., 2014; Tan et al., 2015). These findings suggest that it would be favourable to speak of individual species and preparations rather than 'insects' as a broad category, which might assist in keeping out irrelevant negative associations with the category of insects in general. It might thus be effective to develop species-specific terminology that sound more appealing, or simply adopt the names from the cultures where they are originally from (e.g. 'chapulines', 'zazamushi'), where there is an added assurance that people from other cultures are enjoying the same species. Moreover, given that even those who consume certain types of insects do not necessarily identify themselves as 'insect-eaters', there is then little sense in emphasizing the ubiquity of 'entomophagy', where the use of this term might then instead serve to further marginalise enjoyment of different insect species.

Further research investigating differences in consumer response to 'insects' versus 'edible insects' versus 'food insects', for example, could provide useful insights into different cultural classifications of the 'insects' category and their implications for perceived edibility and 'food-ness'. Further research could also develop and investigate the use of 'beef'/'cow' distinctions for specific insect species, as well as looking further into strategies of naming insect species with new and relevant positive euphemisms (Wansink, 2002), such as 'land shrimp' or 'terra prawn' for certain Orthoptera, or 'galleria' for wax moth larvae, after its genus name (F.V. Dunkel, personal communication).

\section{Food production and procurement}

Many insect species, due to their size and physiology, pose challenges to more conventional concepts of 'meat' and 'livestock' (Deroy et al., 2015). 'Meat' can range in meaning from only skeletal muscular tissue, to include internal organs such as the heart, lungs, liver, and kidneys, to other parts such as tendons and marrow. Depending on the insect species, its developmental stage, and other factors, different people eat different parts, including or excluding parts of the cuticle, legs, and wings. In what ways do different insects demand their own concepts of 'meat'? 
Similarly, to what extent can insects be thought of as 'livestock'? The term 'minilivestock' has already been proposed by Paoletti (2005) and others, which also encompasses 'rodents, frogs, and snails.' Further work should address the benefits and drawbacks of likening insects both to conventional livestock practices with larger animals and to similarly smaller animals but with each their own physiological characteristics and needs when bred and raised. Moreover, it will likely be useful to learn and develop terminology to distinguish between wild and reared insects, especially when the different types of the same or similar species have significantly different nutritional, environmental, and gastronomic properties.

\section{Regulatory policy}

The use of the term 'entomophagy' by the Food and Agriculture Organization of the United Nations since 2012 in its official reports may well have helped to spread the message about the usefulness of insects for food. But indeed, the term leads to simplification of the many issues in the sector. This mechanism can be compared with when the term 'non-timber/wood forest products' was introduced in the early 1990s. While this term had a great impact in drawing attention to funding, policy, legal frameworks and development for the forest sector other than timber, after 25 years the term has lost relevance as preference has shifted to names of specific products (honey, berries, mushrooms, game, tree grubs etc.) We can learn from this general terminology experience: it helps to draw attention during the launching period to have a 'general' technical term, but once attention has been gained, then more specific wording is required.

The current uncertainty in terminology used to describe the consumption of insects may be a barrier to the development of regulations for the use and trade of insects for human consumption in many countries. In most Western countries there are no existing specific regulatory frameworks because insects have not been a common part of most Western diets in modern history, and thus existing terminology, if it exists at all, is very general. Debate about the placement of edible insects within European food safety legislation is ongoing (Halloran, 2014). However, in some cultures where insects have traditionally been consumed and specific terminology for the practice is lacking, such as Thailand, they are treated no differently than other types of food in terms of food safety standards (Halloran et al., 2015c). This normality approach also seems to be how the US Food and Drug Administration (FDA) is currently treating frozen crickets, as any other food-grade frozen product (K. Bachhuber, personal communication, Big Cricket Farms, recently FDA-certified) - which, paired with more specific terminology, could help build constructive legislation.

\section{Conclusions and recommendations for future terminology}

The term 'entomophagy' is relatively new, compared with the long history of humans eating insects. The term's meaning in at least a few European languages has shifted even over the course of its short life, becoming less synonymous with the general eating of insects and several other arthropods by any organism and more specifically referring to human insect-eating practices. This shift does not, however, lessen the term's implicit judgement of human insect-eating from a Western, non-insect-eating paradigm as an animalistic, inappropriate and/or pathological eating/ feeding behaviour - an attitude that may be contributing to the lessening of cultural insect-eating in certain regions of the world.

Use of the term can continue to other members of insecteating cultures, homogenising these diverse practices which can prevent their specific investigation and curtail their idiosyncratic evolution. This diversity of practices also mirrors the diversity of insect species, which an imprecise use of taxonomic categories can obscure. Different cultural traditions engage with different registers of the category 'insect' in different contexts, which inform different approaches not only to classification but also to edibility and cultural appropriateness of foods.

What is an 'insect' and who is an 'insect-eater'? And who gets to decide: the eater, or the non-eating observer - or both, in a process of constant cultural negotiation? The questions raised in this paper go beyond just names and categories - they are also about how individuals and groups build and maintain identities, interact with companion species, and negotiate the structures of power that inform and react to these practices.

There are many directions for further research. Firstly, it would be beneficial to conduct similar historical and literature reviews in non-Western and non-Englishspeaking cultures, both those in which insects are currently eaten and not eaten, focussing on how different cultures classify 'insects' and conceptualise the practice of eating them differently. Furthermore, the implications of these terminological questions for fields such as taxonomy, environmental studies, nutrition, gastronomy, consumer perceptions and acceptance, production and procurement, and regulatory policy, as described above, provide some starting points from which to develop more specific research.

Based on the problems with the current terminology and their implications for future work, we specifically recommend:

- that the category 'insects' in the context of food and feed be used as precisely as possible, whether more narrowly 
(Insecta) or more broadly (including other arthropod and sometimes even non-arthropod invertebrate groups);

- that the term 'entomophagy' be used as little as possible, and when the term be used, that it be done so with an awareness of its conceptual and practical problems and the purpose for its use be specified;

- and that further work focus more on the diversity of insect species, both currently and not currently eaten, and their distinguishing nutritional, environmental, and gastronomic characteristics;

- that the scientific community work to develop more precise and contextual terminologies and vocabularies for this rapidly growing field of research.

\section{Acknowledgements}

Some of the co-authors are supported by grant 32726 from the Velux Foundation (MBF, JE, RF, JEI, ABJ), DANIDA grant 13-06KU (GREEiNSECT) (JEI, ABJ, NR, AH, MHA, SBO), the EU AGTRAIN grant (GMV), the Social Sciences and Humanities Research Council of Canada (SSHRC) Doctoral Fellowships (AH), and the Ministry of Education, Culture, Sports, Science and Technology in Japan (MEXT) (CP). We are also grateful to all collaborators and informants in our different field works who have contributed their time and knowledge.

\section{References}

Aissaoui, M. and Valmalle, P., 2015. Le Petit Larousse et le Petit Robert: les rivaus des motes nouveaux. Le Figaro, Parijs, France. Available at: http://tinyurl.com/p2u24zo.

Anonymous, 1919. La Entomofagia. Ibérica 11: 278-289.

Anonymous, 2001. The holy bible, English standard version. Crossway Bibles, Wheaton, IL, USA.

Anonymous, 2014. Dictionnaire Le Petit Robert. HarperCollins, France, $2880 \mathrm{pp}$.

Ayieko, M.A. and Oriaro, V., 2008. Consumption, indigeneous [sic] knowledge and cultural values of the lakefly species within the Lake Victoria region. African Journal of Environmental Science and Technology 2: 282-286.

Ayieko, M.A., Kinyuru, J.N., Ndong'a, M.F. and Kenji, G.M., 2012. Nutritional value and consumption of black ants (Carebara vidua Smith) from the Lake Victoria Region in Kenya. Advance Journal of Food Science and Technology 4: 39-45.

Bar-Anan, Y., Liberman, N. and Trope, Y., 2006. The association between psychological distance and construal level: Evidence from an implicit association test. Journal of Experimental PsychologyGeneral 135: 609-622.

Barreteau, D., 1999. Les Mofu-Gudur et leurs criquets. In: Baroin, C. and Boutrais, J. (eds.) L'homme et l'animal dans le bassin du lac Tchad - Actes du colloque du reseau Mega-Tchad, Octobre 15-17, 1997, Orleans, France. Editions IRD (Institut de Recherche pour le Developpement), Collection Colloques et Seminaires, no. 00/354. Université Nanterre, Paris, France, pp. 133-169.
Bergier, E., 1941. Peuples entomophages et insects comestibles: ètude sur les moeurs de l'homme et de l'insecte. Imprimerie Rulliere Freres, Avignon, France, 229 pp.

Berlin, B., 1992. Ethnobiological classification: principles of categorization of plants and animals in traditional societies. Princeton University Press, Princeton, NJ, USA, 335 pp.

Bodenheimer, F.S., 1951. Insects as human food. W. Junk, the Hague, the Netherlands, $352 \mathrm{pp}$.

Bukkens, S.G., 1997. The nutritional value of edible insects. Ecology of Food and Nutrition 36: 287-319.

Caparros Megido, R., Sablon, L., Geuens, M., Brostaux, Y., Alabi, T., Blecker, C., Drugmand, D., Haubruge, E. and Francis, F., 2014. Edible insects acceptance by Belgian consumers: promising attitude for entomophagy development. Journal of Sensory Studies 29: 14-20.

Chakravorty, J., Ghosh, S. and Meyer-Rochow, V.B., 2013. Comparative Survey of entomophagy and entomotherapeutic practices in six tribes of Eastern Arunachal Pradesh (India). Journal of Ethnobiology and Ethnomedicine 9: 1-12.

Chapman, A.D., 2006. Numbers of living species in Australia and the world. Australian Biological Resources Study, Canberra, Australia, $80 \mathrm{pp}$.

Christensen, D., Orech, F., Mungai, M., Larsen, T., Friis, H and Aagaard-Hansen, J., 2006. Entomophagy among the Luo of Kenya: a potential mineral source?. International Journal of Food Sciences and Nutrition 57: 198-203.

Costa-Neto, E.M., 2000. The significance of the category 'insect' for folk biological classification systems. Journal of Ecological Anthropology 4: 70-75.

DeFoliart, G.R., 1992. Insects as human food: Gene DeFoliart discusses some nutritional and economic aspects. Crop protection 11: 395-399.

Deroy, O., Reade, B. and Spence, C., 2015. The insectivore's dilemma, and how to take the West out of it. Food Quality and Preference 44: 44-55.

Evans, J., 2014. Labre larver og lækre insekter [Luscious larvae and delicious insects]. moMentum 4: 30-34.

Evans, J., Flore, R., Pedersen, J.A. and Frøst, M.B., 2015. Place-based taste: geography as a starting point for deliciousness. Flavour Journal 4: 7 .

Gordh, G. and Headrick, D., 2011. A dictionary of entomology. CSIRO Publishing, Clayton, Australia, 1520 pp.

Halloran, A., 2014. EU har taget et vigtig skridt [The EU has taken an important step]. moMentum 4: 8-10.

Halloran, A., Flore, R. and Mercier, C, 2015a. Notes from the 'Insects in a gastronomic context' workshop in Bangkok, Thailand. Journal of Insects for Food and Feed 1: 241-243.

Halloran, A., Münke, C., Vantomme, P., Reade, B. and Evans, J., 2015b. Broadening insect gastronomy. In: Sloan, P., Legrand, W. and Hindley, C. (eds.) The Routledge handbook of sustainable food and gastronomy. Routledge, London, UK and New York, NY, USA, 426 pp.

Halloran, A., Vantomme, P., Hanboonsong, Y., and Ekesi, S., 2015c. Regulating edible insects: the challenge of addressing food security, nature conservation, and the erosion of traditional food culture. Food Security 7: 739-746. 
Hanboonsong, Y., Jamjanya, T. and Durst, P. B., 2013. Six-legged livestock: edible insect farming, collection and marketing in Thailand. Food and Agriculture Organisation of the United Nations, Regional Office for Asia and the Pacific, Bangkok, Thailand, 57 pp.

Harris, M., 1985. Good to eat: riddles of food and culture. Simon and Schuster, New York, NY, USA, 289 pp.

Hogue, C.L., 1987. Cultural entomology. Annual Review of Entomology 32: 181-99.

Holt, V., 1885. Why not eat insects? Pryor Publications, Whitstable, UK, 104 pp.

Hooks, B, 1992. Eating the other: desire and resistance. black looks: race and representation. South End Press, New York, NY, USA, 200 pp.

Humle, T. and Matsuzawa, T., 2004. Oil palm use by adjacent communities of chimpanzees at Bossou and Nimba Mountains, West Africa. International Journal of Primatology 25: 551-581.

Johnston, J. and Baumann, S., 2007. Democracy versus distinction: a study of omnivorousness in gourmet food writing. American Journal of Sociology 113: 165-204.

Jongema, Y., 2015. List of edible insects of the world. Wageningen UR, Wageningen, the Netherlands. Available at: http://tinyurl. com/mestm6p.

Kellert, S., 1993. Values and perceptions of invertebrates. Conservation Biology 7: 845-855

Kinyuru, J.N., Kenji, G.M. and Njoroge, M.S., 2009. Process development, nutrition and sensory qualities of wheat buns enriched with edible termites (Macrotermes subhyalinus) from Lake Victoria Region, Kenya. African Journal of Food, Agriculture, Nutrition and Development 9: 1739-1750.

Kinyuru, J.N., Konyole, S.O., Kenji, G.M., Onyango, C.A., Owino, V.O., Owuor, B.O., Estambale, B.B., Friis, H. and Roos, N., 2012. Identification of traditional foods with public health potential for complementary feeding in Western Kenya. Journal of Food Research 1: 148-58.

Laurent, E., 1995. Definition and cultural representation of the category mushi in Japanese culture. Society \& Animals 3: 61-77.

Leer, J. and Kjær, K.M., 2015. Strange culinary encounters: stranger fetishism in Jamie's Italian escape and Gordon's great escape. Food, Culture \& Society 18: 309-327.

Lévy-Luxereau, A., 1980. Note sur quelques criquets de la région de Maradi (Niger) et leur noms Hausa. Journal d'Agriculture Traditionelle et de Botanique Appliquée 37: 263-272.

Looy, H., Dunkel, F.V. and Wood, J.R., 2014. How then shall we eat? Insect-eating attitudes and sustainable foodways. Agriculture and Human Values 31: 131-141.

Lundy, M.E. and Parrella, M.P., 2015. Crickets are not a free lunch: protein capture from scalable organic side-streams via high-density populations of Acheta domesticus. PLoS One 10: e0118785.

Lycett, S.J., Collard, M. and McGrew, W.C., 2007. Phylogenetic analyses of behavior support existence of culture among wild chimpanzees. Proceedings of the National Academy of Sciences 104: 17588-17592.

Martins, Y. and Pliner, P., 2005. Human food choices: an examination of the factors underlying acceptance/rejection of novel and familiar animal and nonanimal foods. Appetite 45: 214-224.
McGrew, W.C., 2001. The other faunivory: primate insectivory and early human diet. In: Stanford, C.B. and Bunn, H.T. (eds.) Meateating and human evolution. Oxford University Press, Oxford, UK, 384 pp.

McGrew, W.C., Linda, F., Marchant, C., Payne, C., Webster, T. and Hunt, K.D., 2010. Chimpanzees at Semliki ignore oil palms. Folia Primatologica 28: 109-121.

Menzel, P. and D'Aluisio, F., 1998. Man eating bugs: the art and science of eating insects. Random House, New York, NY, USA, 192 pp.

Meyer-Rochow, V.B., 1975a. Can insects help to ease the problem of world food shortage? Search 6: 261-262.

Meyer-Rochow, V.B., 1975b. Local taxonomy and terminology for some terrestrial arthropods in five different ethnic groups of Papua New Guinea and central Australia. Journal of the Royal Society of Western Australia 58:15-30.

Meyer-Rochow, V.B., 2009. Food taboos: their origins and purposes. Journal of Ethniobiology and Ethnomedicine 5:1-10.

Meyer-Rochow, V.B., 2010. Entomophagy and its impact on world cultures: the need for a multidisciplinary approach. In: Durst, P.B., Johnson, D.V., Leslie, R.N. and Shono, K. (eds.) Forest insects as food: humans bite back. Proceedings of a workshop on Asia-Pacific resources and their potential for development, 19-21 February 2008, Chiang Mai, Thailand. RAP Publication 2010/02. Food and Agriculture Organization of the United Nations, Bangkok, Thailand, $241 \mathrm{pp}$.

Mielby, L.H. and Frøst, M.B., 2010. Expectations and surprise in a molecular gastronomic meal. Food quality and preference 21: 213-224.

Miokovic, B. and Kozacinski, L., 2003. Role of cheese fly in the production of 'rotten cheese'. Archiv für Lebensmittelhygiene 54: 44-46.

Misof, B., Liu, S., Meusemann, K., Peters, R.S., Donath, A., Mayer, C., Frandsen, P.B., Ware, J., Flouri, T., Beutel, R.G., Niehuis, O., Petersen, M., Izquierdo-Carrasco, F., Wappler, T., Rust, J., Aberer, A.J., Aspöck, U., Aspöck, H., Bartel, D., Blanke, A., Berger, S., Böhm, A., Buckley, T.R., Calcott, B., Chen, J., Friedrich, F., Fukui, M., Fujita, M., Greve, C., Grobe, P., Gu, S., Huang, Y., Jermiin, L.S., Kawahara, A.Y., Krogmann, L., Kubiak, M., Lanfear, R., Letsch, H., Li, Y., Li, Z., Li, J., Lu, H., Machida, R., Mashimo, Y., Kapli, P., McKenna, D.D., Meng, G., Nakagaki, Y., Navarrete-Heredia, J.L., Ott, M., Ou, Y., Pass, G., Podsiadlowski, L., Pohl, H., Von Reumont, B.M., Schütte, K., Sekiya, K., Shimizu, S., Slipinski, A., Stamatakis, A., Song, W., Su, X., Szucsich, N.U., Tan, M., Tan, X., Tang, M., Tang, J., Timelthaler, G., Tomizuka, S., Trautwein, M., Tong, X., Uchifune, T., Walzl, M.G., Wiegmann, B.M., Wilbrandt, J., Wipfler, B., Wong, T.K., Wu, Q., Wu, G., Xie, Y., Yang, S., Yang, Q., Yeates, D.K., Yoshizawa, K., Zhang, Q., Zhang, R., Zhang, W., Zhang, Y., Zhao, J., Zhou, C., Zhou, L., Ziesmann, T., Zou, S., Li, Y., Xu, X., Zhang, Y., Yang, H., Wang, J., Wang, J., Kjer, K.M., Zhou, X., 2014. Phylogenomics resolves the timing and pattern of insect evolution. Science 346: 763-767.

Novotny, V., Basset, Y., Miller, S.E., Weiblen, G.D., Bremer, B., Cizek, L. and Drozd, P., 2002. Low host specificity of herbivorous insects in a tropical forest. Nature 416: 841-844.

Obopile, M. and Seeletso, T.G., 2013. Eat or not eat: an analysis of the status of entomophagy in Botswana. Food security 5: 817-824. 
O'Malley, R. and McGrew, W.C., 2014. Primates and insect resources, Journal of Human Evolution 71: 1-3.

Paoletti, M.F. (ed), 2005. Ecological implications of minilivestock: potential of insects, rodents, frogs, and snails. Science Publishers, Enfield, NH, USA, 648 pp.

Pennisi, E., 2015. All in the (bigger) family: revised arthropod tree marries crustacean and insect fields. Science of the Total Environment 347: 220-221.

Posey, D.A., 1984. Hierarchy and utility in a folk biological taxonomic system: patterns in classification of arthropods by the Kayapó Indians of Brazil. Journal of Ethnobiology 4: 123-139.

Ramos-Elorduy, J., Moreno, J.M.P., Prado, E.E., Perez, M.A., Otero, J.L. and De Guevara, O.L., 1997. Nutritional value of edible insects from the state of Oaxaca, Mexico. Journal of food composition and analysis 10: 142-157.

Raubenheimer, D. and Rothman, J.M., 2013. Nutritional ecology of entomophagy in humans and other primates. Annual Review of Entomology 58: 141-60.

Riley, C.V., 1871. Sixth annual report on the noxious, beneficial and other insects of the State of Missouri. Hegan \& Carter, Jefferson City, MO, USA, p. 144. Available at: http://tinyurl.com/qa93odk.

Rozin, P, 1990. Development in the food domain. Developmental Psychology 26: 555-562.

Rozin, P. and Fallon, A.E., 1987. A perspective on disgust. Psychological Review 94: 23-41.

Rozin, E. and Rozin, P., 1981. Culinary themes and variations. Natural History 90: 6-10.

Ruby, M.B., Rozin, P. and Chan, C., 2015. Determinants of willingness to eat insects in the USA and India. Journal of Insects as Food and Feed 1: 215-225.

Ryan, L.G., 1996. Insect musicians and cricket champions: a cultural history of singing insects in China and Japan. China Books \& Periodicals, Inc., San Francisco, CA, USA.

Schiefenhövel, W. and Blum., P., 2007. Insects: forgotten and rediscovered as food. In: MacClancy, J., Henry, J. and Macbeth, H. (eds.) Consuming the inedible: neglected dimensions of food choice. Berghahn Books, New York, NY, USA, 258 pp.

Schimitschek, E., 1961. Die Bedeutung der Insekten für die Kultur und Wirtschaft des Menschen in Vergangenheit und Gegenwart (Boceklerin, insanligin geccmisteki vebugunku kultur ve iktis hayattaki onemi). Übersetzung Uslu, S. Orman Fakiiltesi konferanslari 1959, Istanbul Universitesi 908: 1-48.

Schimitschek, E., 1968. Insekten als Nahrung, in Brauchtum, Kult und Kultur. In: Helmcke, J.-G., Stark, D. and Wermuth, H. (eds.) Handbuch der Zoologie - eine Naturgeschichte der Stämme des Tierreichs, Band 4. Akademie Verlag, Berlin, Germany, pp. 1-62.
Sileshi, G.W., Nyeko, P., Nkunika, P.O.Y., Sekematte, B.M., Akinnifesi, F.K. and Ajayi, O.C., 2009. Integrating ethno-ecological and scientific knowledge of termites for sustainable termite management and human welfare in Africa. Ecology and Society 14: 48.

Simoons, F.J., 1974. Rejection of fish as human food in Africa: a problem in history and ecology. Ecology of Food and Nutrition 3: 89-105.

Simoons, F.J., 1978. Traditional use and avoidance of foods of animal origin: a culture historical view. Cultural Food Patterns and Nutrition, 28: 178-184.

Tan, H.S.G., Fischer, A.R.H., Tinchan, P., Stieger, M., Steenbekkers, L.P.A. and Van Trijp, H.C.M., 2015. Insects as food: exploring cultural exposure and individual experience as determinants of acceptance. Food Quality and Preference 42: 78-89.

Tuorila, H.M., Meiselman, H.L., Cardello, A.V. and Lesher, L.L., 1998. Effect of expectations and the definition of product category on the acceptance of unfamiliar foods. Food Quality and Preference 9: 421-430.

Turner, N.J., Łuczaj, Ł.J., Migliorini, P., Pieroni, A., Dreon, A.L., Sacchetti, L.E. and Paoletti, M.G., 2011. Edible and tended wild plants, traditional ecological knowledge and agroecology. Critical Reviews in Plant Sciences 30: 198-225.

Van Huis, A., 2003. Insects as food in sub-Saharan Africa. Insect Science and its Application 23: 163-85.

Van Huis, A., Van Itterbeeck, J., Klunder, H., Mertens, E., Halloran, A., Muir, G. and Vantomme, P., 2013. Edible insects: future prospects for food and feed. Food and Agriculture Organisation of the United Nations, Rome, Italy, 190 pp.

Van Huis, A., Dicke, M. and Van Loon, J.J.A., 2015. Insects to feed the world. Journal of Insects as Food and Feed 1: 3-5.

Virey, J.J., 1810. De l'entomophagie ou de la nourriture tirée des insectes chez différens peuples et de ses effets sur l'économie animale. Dictionnaire des Sciences Médicinale, Paris, France.

Wansink, B., 2002. Changing eating habits on the home front: lost lessons from World War II research. Journal of Public Policy and Marketing 21: 90-99.

Wansink, B., Van Ittersum, K. and Painter, J.E., 2005. How descriptive food names bias sensory perceptions in restaurants. Food Quality and Preference 16: 393-400.

Webster, T.H., McGrew, W.C., Marchant, L.F., Payne, C.L. and Hunt, K.D., 2014. Selective insectivory at Toro-Semliki, Uganda: Comparative analyses suggest no 'savanna' chimpanzee pattern. Journal of Human Evolution 71: 20-27.

Yates-Doerr, E, 2012. Meeting the demand for meat? Anthropology Today 28: 1 
